\title{
Neuronal Activity and Glutamate Uptake Decrease Mitochondrial Mobility in Astrocytes and Position Mitochondria Near Glutamate Transporters
}

\author{
Joshua G. Jackson, ${ }^{1,2}$ John C. O'Donnell, ${ }^{3}$ Hajime Takano, ${ }^{1,2}$ Douglas A. Coulter, ${ }^{1,2,4}$ and Michael B. Robinson ${ }^{1,2,3}$ \\ ${ }^{1}$ Children's Hospital of Philadelphia Research Institute, ${ }^{2}$ Department of Pediatrics, ${ }^{3}$ Department of Pharmacology, and ${ }^{4}$ Department of Neuroscience, \\ University of Pennsylvania, Philadelphia, Pennsylvania 19104
}

\begin{abstract}
Within neurons, mitochondria are nonuniformly distributed and are retained at sites of high activity and metabolic demand. Glutamate transport and the concomitant activation of the $\mathrm{Na}^{+} / \mathrm{K}^{+}$-ATPase represent a substantial energetic demand on astrocytes. We hypothesized that mitochondrial mobility within astrocytic processes might be regulated by neuronal activity and glutamate transport. We imaged organotypic hippocampal slice cultures of rat, in which astrocytes maintain their highly branched morphologies and express glutamate transporters. Using time-lapse confocal microscopy, the mobility of mitochondria within individual astrocytic processes and neuronal dendrites was tracked. Within neurons, a greater percentage of mitochondria were mobile than in astrocytes. Furthermore, they moved faster and farther than in astrocytes. Inhibiting neuronal activity with tetrodotoxin (TTX) increased the percentage of mobile mitochondria in astrocytes. Mitochondrial movement in astrocytes was inhibited by vinblastine and cytochalasin $\mathrm{D}$, demonstrating that this mobility depends on both the microtubule and actin cytoskeletons. Inhibition of glutamate transport tripled the percentage of mobile mitochondria in astrocytes. Conversely, application of the transporter substrate D-aspartate reversed the TTX-induced increase in the percentage of mobile mitochondria. Inhibition of reversed $\mathrm{Na}^{+} / \mathrm{Ca}^{2+}$ exchange also increased the percentage of mitochondria that were mobile. Last, we demonstrated that neuronal activity increases the probability that mitochondria appose GLT-1 particles within astrocyte processes, without changing the proximity of GLT-1 particles to VGLUT1. These results imply that neuronal activity and the resulting clearance of glutamate by astrocytes regulate the movement of astrocytic mitochondria and suggest a mechanism by which glutamate transporters might retain mitochondria at sites of glutamate uptake.
\end{abstract}

Key words: astrocyte; GLT-1; glutamate; mitochondria; mobility; transporter

\section{Introduction}

Astrocytes express a large cohort of neurotransmitter receptors and transporters that allow them to sense and respond to neuronal stimuli. They possess enormously elaborate processes that contact synapses and the vasculature. A single astrocyte domain can contact tens of thousands of synapses (Halassa et al., 2007b), thus allowing astrocytes to monitor the activity of a large number of synapses (Newman, 2003).

Received Aug. 14, 2013; revised Nov. 26, 2013; accepted Dec. 9, 2013.

Author contributions: J.G.J., J.C.O., H.T., D.A.C., and M.B.R. designed research; J.G.J. and J.C.O. performed research; J.G.J. contributed unpublished reagents/analytic tools; J.G.J., J.C.O., H.T., and D.A.C. analyzed data; J.G.J., J.C.O., and M.B.R. wrote the paper.

This work was supported by a grant (R01 NS077773) to M.B.R. from the National Institute of Neurological Disorders and Stroke. J.C.0. is supported by a predoctoral training grant in pharmacology (T32-GM008076-28). J.G.J was partially supported by T32NS007413. The Institutional Intellectual and Developmental Disabilities Research Center P30 HD26979 Cellular Neuroscience Core also provided valuable support for these studies. We thank Dr. Rita Balice-Gordon for the use of equipment. We also thank members of the Robinson and Coulter laboratories for their advice and suggestions during this research.

Correspondence should be addressed to Michael B. Robinson, Department of Pediatrics, 502N, Abramson Pediatric Research Building, 3615 Civic Center Boulevard, Philadelphia, PA 19104-3779. E-mail: Robinson@mail.med.upenn.edu.

DOI:10.1523/JNEUROSCI.3510-13.2014

Copyright $\odot 2014$ the authors $\quad 0270-6474 / 14 / 331613-12 \$ 15.00 / 0$
Glutamate is the principle excitatory neurotransmitter in the CNS. Synaptic levels of glutamate are kept low $(\sim 25 \mathrm{nM})$, against brain levels that approach $10 \mathrm{mmol} / \mathrm{kg}$ (Herman and Jahr, 2007), to ensure appropriate excitatory signaling and to limit excessive activation of glutamate receptors that can cause excitotoxicity (for review, see Choi, 1992; Conti and Weinberg, 1999). Extracellular glutamate is cleared via a family of $\mathrm{Na}^{+}$-dependent glutamate transporters (for review, see Danbolt, 2001; Sheldon and Robinson, 2007).

These transporters couple the inward movement of glutamate to the inward movement of three $\mathrm{Na}^{+}$ions and $1 \mathrm{H}^{+}$ion, and the outward movement of one $\mathrm{K}^{+}$ion, providing the energy to maintain up to a millionfold concentration gradient of glutamate (Zerangue and Kavanaugh, 1996). Because of this coupling, glutamate uptake results in a significant increase in the $\mathrm{Na}^{+}$concentration within the fine astrocytic processes (Rose and Ransom, 1996; Bergles and Jahr, 1997). Glutamate uptake also activates the $\mathrm{Na}^{+} / \mathrm{K}^{+}$-ATPase in astrocytes, an effect attributed to increased $\mathrm{Na}^{+}$concentration (Magistretti and Pellerin, 1999). Not surprisingly, the glial glutamate transporters colocalize and physically interact with $\mathrm{Na}^{+} / \mathrm{K}^{+}$-ATPase isoforms, glycolytic enzymes, and mitochondria (Rose et al., 2009; Genda et al., 2011; Bauer et al., 
2012) and glutamate uptake is functionally coupled to increases in glucose uptake, glycolysis, and oxidative phosphorylation (Pellerin and Magistretti, 1994; Loaiza et al., 2003; Magistretti, 2006).

While much research has examined the link between glutamate uptake and glycolysis, the role of mitochondria in astrocytes is often overlooked. Astrocytes have a high oxidative metabolism (Hertz et al., 2007) and possess a large number of mitochondria, even in the very fine processes (Lovatt et al., 2007; Ito et al., 2009; Lavialle et al., 2011; for review, see Parpura and Verkhratsky, 2012). In neurons, mitochondria are not uniformly distributed; instead mitochondria are concentrated at sites with heightened demand for ATP or $\mathrm{Ca}^{2+}$ buffering, including at axon branches, synapses, nodes of Ranvier, and growth cones. This distribution is established by movement of mitochondria along the microtubule and actin cytoskeleton (Morris and Hollenbeck, 1995; Ligon and Steward, 2000; Hollenbeck, 2005; Genda et al., 2011). Little is known about the mechanisms regulating transport of mitochondria in astrocytes.

Here, we present the first description of mobile mitochondria within the processes of astrocytes. We provide evidence that the movement of mitochondria in astrocytic processes is regulated by neuronal activity, astrocytic glutamate uptake, and reversed $\mathrm{Na}^{+} / \mathrm{Ca}^{2+}$ exchange. Furthermore, we demonstrate that neuronal activity increases the probability that mitochondria appose GLT-1 protein in astrocyte processes. We suggest that regulation of mitochondrial mobility may represent a mechanism to retain mitochondria near sites of glutamate uptake in astrocytes.

\section{Materials and Methods}

cDNA constructs. pBluescript-Gfa $\mathrm{ABC1D}_{\mathrm{D}}$ was a gift from Dr. Michael Brenner (University of Alabama-Birmingham). This construct encodes a $681 \mathrm{bp}$ fragment of the glial fibrillary acidic protein (GFAP) promoter that is sufficient to result in selective expression in astrocytes throughout the CNS (Lee et al., 2008). This 681 bp GFAP promoter fragment was inserted into pTY-CMV-mCherry between Nhe1 and Age1 restriction sites to form pTY-Gfa ${ }_{\mathrm{ABC} 1 \mathrm{D}}-\mathrm{mCherry}$ and was a gift from Dr. John Wolf

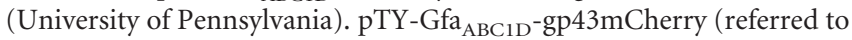
as $\mathrm{Gfa}_{\mathrm{ABC1D}}$-mCherry) was generated by PCR amplification of the membrane-targeting myristoylation sequence of gap43 into pTY$\mathrm{Gfa}_{\mathrm{ABC} 1 \mathrm{D}}$-mCherry immediately after the initiating methionine of mCherry. pEGFP-mito (a gift from Dr. Stanley Thayer, University of Minnesota, Minneapolis) is a fusion of EGFP with the mitochondrial matrix targeting sequence from CoxVIII and has been shown to result in specific targeting of EGFP into mitochondria (Rizzuto et al., 1993; Wang et al., 2003).

Reagents. Rabbit anti-GLT-1 was a gift from Dr. Jeffrey Rothstein (Johns Hopkins University). Rabbit anti-GFAP polyclonal antibody and D-aspartate were purchased from Sigma-Aldrich. Rabbit antiMAP2 and guinea pig anti-VGLUT1 were purchased from Millipore. Highly cross-adsorbed secondary antibodies conjugated to Alexa Fluor dyes were purchased from Invitrogen. Goat anti-rabbit antibody conjugated to Dylight 405 was purchased from ThermoFisher Scientific. Tetrodotoxin (TTX) was purchased from Alomone Labs. Vinblastine, cytochalasin D, 6,7-dinitroquinoxaline-2,3-dione (DNQX), D-(-)-2-amino-5-phosphonopentanoic acid (D-APV), bicuculline, (3S)3-[[3-[[4-(trifluoromethyl)benzoyl] amino]phenyl]methoxy]-L-aspartic acid (TFB-TBOA), (S)-3,5-dihydroxyphenylglycine (DHPG), 2-methyl6-(phenylethynyl)pyridine hydrochloride (MPEP), 2-[2-[4-(4-nitrobenzyloxy) phenyl] ethyl isothiourea mesylate (KB-R7943), and $N$-[(3-aminophenyl) methyl]-6-[4-[(3-fluorophenyl) methoxy] phenoxy]-3-pyridine carboxamide dihydrochloride (YM 244769) were purchased from Tocris Bioscience.

Slice culture and transfection. Organotypic cultures of rat hippocampus were prepared as previously described (Benediktsson et al., 2005; Kayser et al., 2006; Genda et al., 2011).
Six-to-12-d-old rat pups of either sex were decapitated and their brains removed into sucrose artificial CSF (aCSF) composed of the following (in mM): 280 sucrose, $5 \mathrm{KCl}, 1 \mathrm{MgCl}_{2}, 2 \mathrm{CaCl}_{2}, 20$ glucose, and 10 HEPES. Hippocampal slices $(300 \mu \mathrm{m})$ were prepared using a Mcllwain tissue chopper (Brinkman Instruments) and placed on $0.4 \mu \mathrm{m}$ Millicell culture inserts (Millipore) in six-well plates. Slices were maintained in a humidified incubator with $5 \% \mathrm{CO}_{2}$ at $37^{\circ} \mathrm{C}$ with $1 \mathrm{ml}$ of medium containing the following: $50 \%$ Neurobasal medium, 25\% horse serum, $25 \%$ HBSS, supplemented with $10 \mathrm{~mm}$ HEPES, $36 \mathrm{~mm}$ glucose, $2 \mathrm{~mm}$ glutamine, $10 \mathrm{U} / \mathrm{ml}$ penicillin, and $100 \mu \mathrm{g} / \mathrm{ml}$ streptomycin, $\mathrm{pH} 7.2-7.3$. Slices were allowed to recover for $2 \mathrm{~d}$ before transfection with plasmids encoding a mitochondrial-targeted EGFP (EGFP-mito) and $\mathrm{Gfa}_{\mathrm{ABClD}^{-}}$ mCherry fluorescent protein using a Helios Gene-Gun (Bio-Rad; McAllister, 2004; Benediktsson et al., 2005). Gene gun bullets were generated as follows: cDNAs ( $10 \mu \mathrm{g}$ of total) were combined with $8-10 \mu \mathrm{g}$ of 1.0 or $1.6 \mu \mathrm{m}$ gold particles (Bio-Rad) in a solution of $0.02 \mathrm{mg} / \mathrm{ml}$ polyvinylpyrrolidone 20, $0.05 \mathrm{M}$ spermidine, and $1 \mathrm{M} \mathrm{CaCl}_{2}$. This suspension was used to coat Teflon tubing that was subsequently cut and loaded into the gene gun. The cDNA-coated gold particles were shot using highpressure helium (100-120 psi) into cultured slices in inserts sitting on warmed agarose slabs. We used $1.0 \mu \mathrm{m}$ gold particles for transfection of astrocytes and $1.6 \mu \mathrm{m}$ particles for the nonselective transfection of astrocytes and neurons (Benediktsson et al., 2005).

Live slice imaging. Two days after transfection, slices were excised from their membrane supports and placed in a closed, flow-through chamber for imaging. Slices were continuously superfused with heated $\left(34^{\circ} \mathrm{C}\right)$ aCSF composed of the following (in $\mathrm{mm}$ ): $130 \mathrm{NaCl}, 3 \mathrm{KCl}, 1.25$ $\mathrm{NaH}_{2} \mathrm{PO}_{4}, 26 \mathrm{NaHCO}_{3}, 10$ glucose, $1 \mathrm{MgCl}_{2}, 2 \mathrm{CaCl}_{2}$. This solution was continuously bubbled with $95 \% \mathrm{O}_{2} / 5 \% \mathrm{CO}_{2}$. Slices were imaged on an Olympus Fluoview 1000 laser scanning confocal microscope equipped with a $40 \times$ UPlanApo objective (numerical aperture, 1.4). Slices were allowed to equilibrate in the imaging chamber for $10 \mathrm{~min}$ before imaging. Cells expressing EGFP-mito and/or membrane-targeted mCherry were identified using epifluorescence and were imaged using the 488 and 546 $\mathrm{nm}$ laser lines, respectively (Fig. $1 B-G$ ). To control for possible cultureto-culture variability in the percentage of mobile mitochondria, all experiments included control and experimental slices from the same cultures and were imaged on the same day. Cells were visually selected based on their complex morphology and lack of reactive phenotype. Cells at the surface of the slice or at the slice margins were not imaged. Image stacks (15-25 optical sections, $1 \mu \mathrm{m} z$-spacing) were collected from the identified cell to aid in retrospective identification. A subfield of processes was identified and was imaged at $512 \times 512$ pixels with an additional $4-5 \times$ digital zoom. Image stacks (3-8 optical sections, $1 \mu \mathrm{m}$ $z$-spacing) were collected every $6-10 \mathrm{~s}$ for $15 \mathrm{~min}$ from a field containing $3-8$ astrocyte processes and $\geq 10$ mitochondria. Under these conditions, we did not observe significant decreases in fluorescence intensity with time (Fig. 1A). We also did not observe evidence of cell swelling during the imaging epochs as examined with the membrane-targeted mCherry.

Immediately following the imaging epoch, slices were removed from the chamber and immersed in $4 \%$ paraformaldehyde in PBS ( $0.1 \mathrm{M}$ PBS). Tissues were processed as free-floating sections for subsequent immunostaining. These sections were extracted for $1 \mathrm{~h}$ in a solution of PBS and $1 \%$ Triton X-100 at room temperature. Sections were blocked in $5 \%$ goat serum for $1 \mathrm{~h}$ at room temperature and incubated with primary antibodies against GFAP (1:100; Sigma-Aldrich) or MAP2 (1:100; Millipore) for $2 \mathrm{~d}$ at $4^{\circ} \mathrm{C}$ in a solution containing $1 \%$ Triton X-100 and 5\% goat serum. Sections were rinsed three times for $15 \mathrm{~min}$ each in PBS and incubated overnight with secondary antibody (goat anti-rabbit or mouse Alexa Fluor 633; Invitrogen). Slices were rinsed three times for $15 \mathrm{~min}$ each in PBS before mounting on precoated slides (Superfrost Plus, Fisher Scientific). Sections were imaged on a laser confocal microscope as described above (Fig. 1A).

Although there is evidence that the smaller gold particles $(1 \mu \mathrm{m}) \mathrm{se}-$ lectively transduce astrocytes (Benediktsson et al., 2005), a GFAP promoter-driven mCherry was used to ensure selectivity (Lee et al., 2008). To confirm that the combination of $1.0 \mu \mathrm{m}$ gold particles with this promoter fragment results in selective expression in astrocytes in this system, cells expressing the $\mathrm{Gfa}_{\mathrm{ABClD}}$-driven mCherry fluorescent pro- 
A

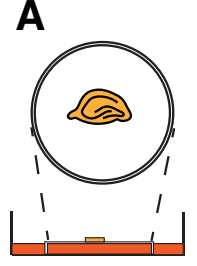

ODIV
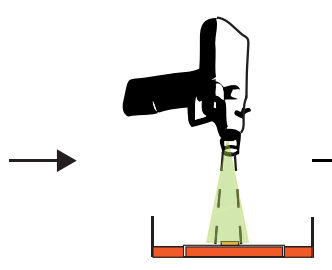

2DIV

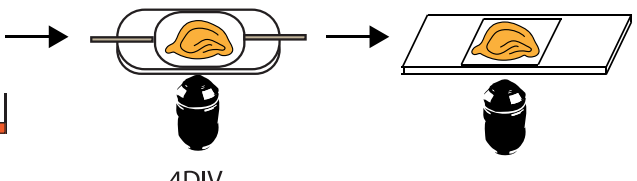

4DIV
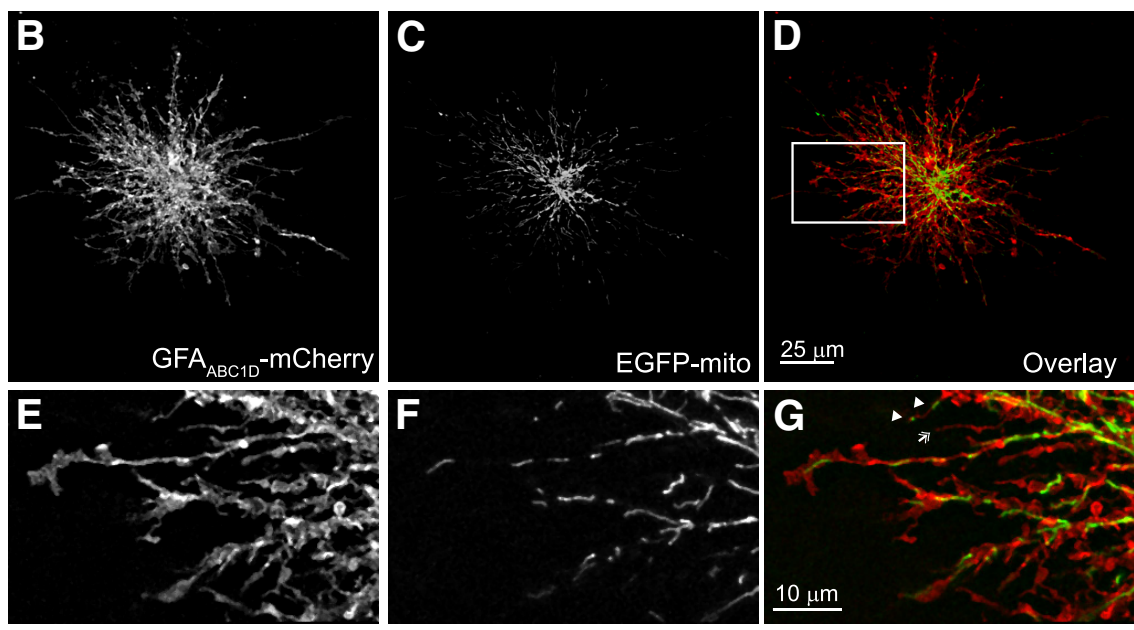

Figure 1. Method for imaging of astrocytic mitochondria in hippocampal organotypic cultures. $A$, Schematic summary of the experimental approach. Hippocampi from early postnatal rat pups were isolated and plated onto membranes. Two days later, slices were transfected via particle-based biolistics. Slices were imaged at 4 DIV via confocal microscope. Slices were subsequently fixed for immnofluorescent analysis. $\boldsymbol{B}-\boldsymbol{G}$, Representative images of an astrocyte in hippocampal slice culture transfected with a membrane-targeted mCherry fluorescent protein driven by a minimal GFAP promoter $\left(\mathrm{GFA}_{A B C 1 D^{-}}-\mathrm{mCherry} ; \boldsymbol{B}, \boldsymbol{E}, G F A_{A B C 1 D^{-}}\right.$ $m$ Cherry) and a mitochondrial matrix-targeted enhanced green fluorescent protein ( $\boldsymbol{C}, \boldsymbol{F}$, EGFP-mito) and overlay ( $\boldsymbol{D}, \boldsymbol{G})$. EGFP fluorescence is shown as green and $\mathrm{GFA}_{\mathrm{ABC} 1 D^{-}}-\mathrm{mCherry}$ as red. Scale bar, $25 \mu \mathrm{m}$. $\boldsymbol{E}-\mathbf{G}$, Magnified views of the astrocyte processes depicted in $\boldsymbol{D}$ (white box). Mitochondria are present in some ( $\boldsymbol{G}$, arrowhead), but not all (chevron) of the small astrocyte processes. Scale bar, $10 \mu \mathrm{m}$.

tein were tested for colocalization with the astrocytic marker GFAP. In four randomly chosen experiments, all cells expressing $\mathrm{Gfa}_{\mathrm{ABC} 1 \mathrm{D}}$-driven mCherry fluorescent protein also expressed GFAP immunoreactivity (data not shown). To confirm neuronal identity, we immunostained every slice previously used to examine mitochondrial mobility in neurons with antibodies against the dendritic marker MAP2. The process used for dynamic imaging was reidentified in the fixed and immunostained slices. Every process was confirmed to come from a neuronal dendrite (data not shown).

Image analysis. All data analyses were performed by individuals who were blinded to condition for the particular day. All images were processed using National Institutes of Health ImageJ software (http://rsb. info.nih.gov/ij/; Schneider et al., 2012). Images were backgroundcorrected and filtered using a Gaussian filter $(\sigma=1)$. Maximal projections of image stacks were generated. Motion artifacts due to slice drift were corrected using the TurboReg plugin of ImageJ to implement rigid registration. This aligned all images in a time-lapse series to the original image. The resulting movies were used to examine the mobility of individual mitochondria within the processes of neurons or astrocytes. Individual mitochondria were tracked using the MTrackJ plugin to ImageJ (Meijering et al., 2012). A mitochondrion was considered mobile if the displacement exceeded $2 \mu \mathrm{m}$ within the $15 \mathrm{~min}$ imaging window. Anterograde and retrograde motions were defined relative to the cell body. Kymographs (displacement vs time) were constructed for individual astrocytic processes for display purposes. Kymographs are displayed such that time is on the $y$-axis (time passes from top to bottom of image). Mitochondria that are stationary appear as vertical lines, while mitochondria that moved over the imaging period will appear as diagonal lines.

Puncta analysis. The distribution of GLT-1 particles relative to mitochondria and synapses was analyzed in the manner of MacAskill et al.
(2010) as detailed below. Hippocampal slice cultures were transfected with EGFP-mito and $\mathrm{Gfa}_{\mathrm{ABC1D}}$-mCherry as described above. Slices were immersed in prewarmed $\left(34^{\circ} \mathrm{C}\right)$, oxygenated aCSF in the absence or presence of TTX (1 $\mu \mathrm{M})$ for $30 \mathrm{~min}$. Slices were immediately immersed in $4 \%$ paraformaldehyde (0.1 M PBS) and processed as described earlier in the Materials and Methods section. These sections were incubated with primary antibodies against GLT-1 (1:100) or VGLUT1 (1:200; Millipore) and visualized with fluorescent moleculeconjugated secondary antibodies [goat antirabbit Dylight 405 (1:400) or goat anti-guinea pig AlexaFluor 633 (1:400)].

Slices were visualized on an Olympus laser scanning confocal microscope equipped with a $40 \times$ (numerical aperture 1.4) objective at an additional $5 \times$ optical zoom, using the 405 , 488, 546, and $633 \mathrm{~nm}$ laser lines. All images were collected sequentially to avoid contamination of signals from other fluorophores. Sections from each experiment were singly labeled or transfected to verify that the signal measured was specific.

Single optical sections were background corrected and filtered using a Gaussian filter $(\sigma=$ $1)$. mCherry fluorescent images were used to create binary masks that were applied to GLT-1 immunofluorescent images, thus defining GLT-1 immunoreactivity within single astrocyte processes. Mitochondria and GLT-1 puncta were identified by thresholding at 3.5 times the SD of the mean image and converted to binary (Genda et al., 2011). VGLUT1 particles were thresholded using an autolocal thresholding plugin to the FIJI implementation of ImageJ (Gabriel Landini) and converted to binary. The coordinates (centroid) of all particles were recorded and used to calculate the minimum distance between mitochondria-GLT-1 and GLT-1VGLUT ${ }^{+}$pairs. Using this same dataset, we used Matlab to also determine the distance between the edge of each mitochondrion and the edge of the nearest GLT-1 particle. These results are displayed as cumulative probabilities.

Statistics. All data are presented as mean \pm SEM of separate cells that were acquired from at least three independent sets of experiments (separate sets of slices prepared on separate days). Statistical significance was assessed by unpaired Student's $t$ test or ANOVA with Bonferroni's multiple-comparisons test. Statistical significance between cumulative probability distributions was determined using the Kolmogorov-Smirnov test. Statistical analysis was conducted using Graphpad Prism software

\section{Results}

\section{Mitochondrial mobility in astrocyte processes}

While numerous groups (for review, see Cai and Sheng, 2009; MacAskill and Kittler, 2010; Schwarz, 2013) have examined mitochondrial movement in dissociated cultures of neurons, few have looked at mitochondrial movement in neurons in more complex systems (Ohno et al., 2011) and none have examined mitochondrial movement within the processes of astrocytes. Here, we used organotypic cultures of rat hippocampus to examine the mobility of mitochondria in the processes of astrocytes and neuronal dendrites. Transverse sections of rat hippocampus were cultured on membrane inserts for $2 \mathrm{~d}$. Cultures were transfected via a gene gun with plasmids encoding EGFP-mito and a membrane-targeted mCherry fluorescent protein and visualized 

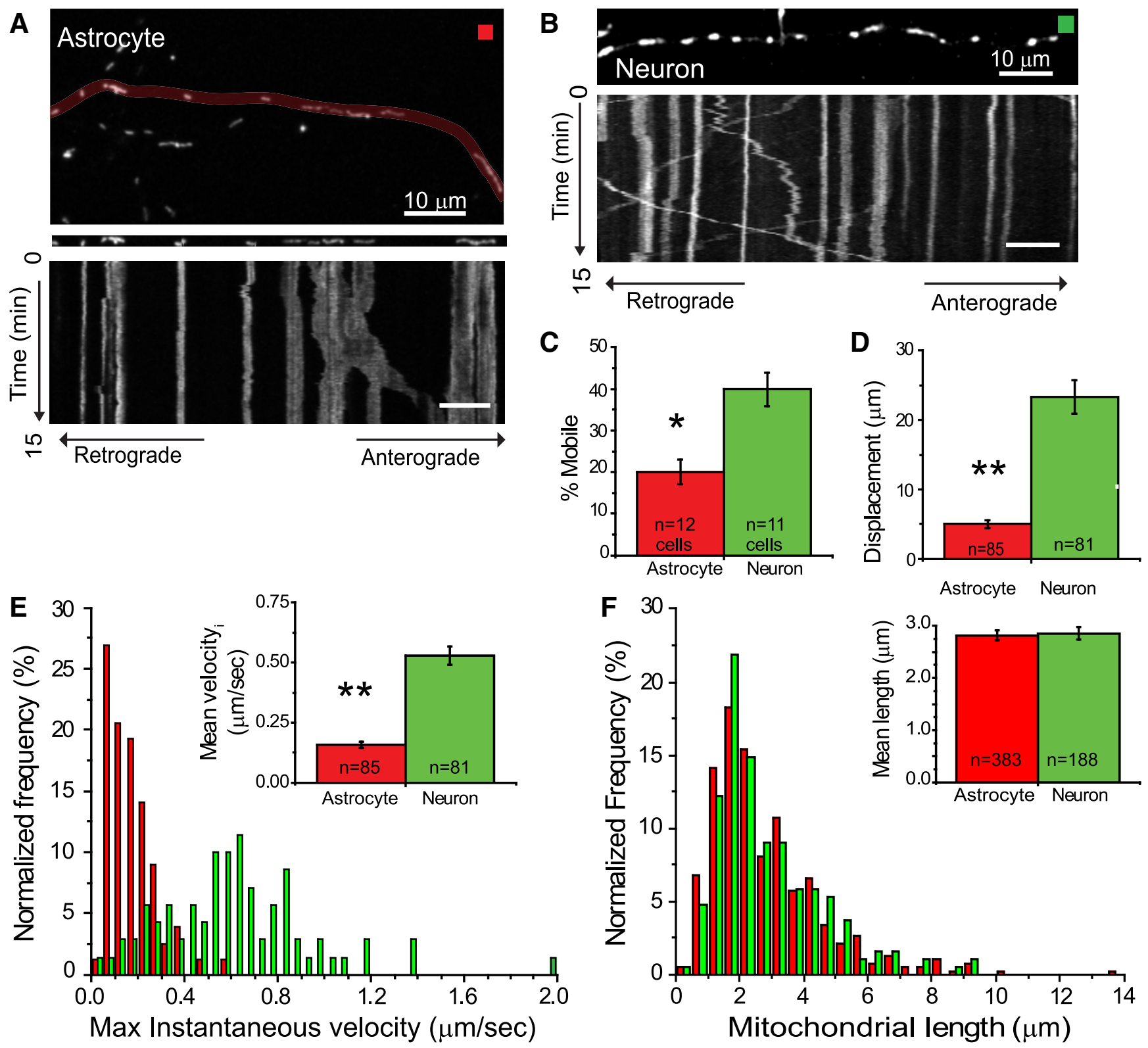

Figure 2. Comparison of mitochondrial mobility in astrocytes and neurons in organotypic cultures of hippocampus. Mitochondria in astrocytes and neurons were transfected with plasmids encoding EGFP-mito and a membrane-targeted mCherry fluorescent protein. Representative images of astrocytic ( $\boldsymbol{A}$, red box) and neuronal ( $\boldsymbol{B}$, green box) processes are displayed above kymographs that depict the movement of mitochondria in these processes over a 15 min imaging epoch (time passes from top to bottom of image). Stationary mitochondria are seen as straight lines and moving mitochondria as diagonal lines. Scale bar, $10 \mu \mathrm{m}$. C, Histogram depicts the percentage of mitochondria in astrocytes and neurons that were mobile during the imaging epoch, normalized to the total number of mitochondria that were visualized during that period. Results are mean \pm SEM. $\boldsymbol{D}$, Histogram displays the average displacement of individual mobile mitochondria. $\boldsymbol{E}$, Normalized frequency distribution depicts the maximal instantaneous velocity of individual mitochondria that were mobile within astrocytes (red) and neurons (green). The mean maximal velocity of mobile mitochondria is depicted in inset histogram. $\boldsymbol{F}$, Normalized frequency distribution of mitochondrial lengths (mobile and stationary) in astrocytes (red) and neurons (green). The mean length (micrometers) of mitochondria in astrocytes and neurons is depicted in inset. ${ }^{*} p<0.05 ;{ }^{* *} p<0.005$, unpaired Student's $t$ test.

$2 \mathrm{~d}$ later (Fig. 1A). Astrocytes in organotypic cultures maintain much of their characteristic three-dimensional morphology (Fig. $1 B-G)$, with many fine processes radiating from the cell body and the presence of numerous fine branchlets (Benediktsson et al., 2005). EGFP-expressing mitochondria were readily identifiable within the astrocyte processes (Fig. 1C,F). Mitochondria are capable of investing into very small $(<0.6 \mu \mathrm{m}$ diameter) processes, where they occupy a substantial portion of the width of some (Fig. 1G, white arrowheads) but not all (white chevron) of these processes. Mitochondria within the processes of astrocytes and neurons exist as discrete organelles, whereas those localized to the cell body appear to form a reticular structure, making individual mitochondria more difficult to identify. For our studies of mitochondrial mobility, we confined our analysis to the smaller processes of the astrocyte, where single mitochondria are readily identifiable.

We compared the mobility of mitochondria within individual astrocytes and neuronal dendrites using time-lapse confocal microscopy (Fig. 2A,B). The majority of mitochondria were stationary for the duration of the 15 min imaging window within both the neurons and astrocytes. However, significantly more mitochondria were mobile within the dendrites of the neurons than in astrocytic processes (Fig. 2C). The movement of mitochondria within astrocytes and neurons was bidirectional. In as- 

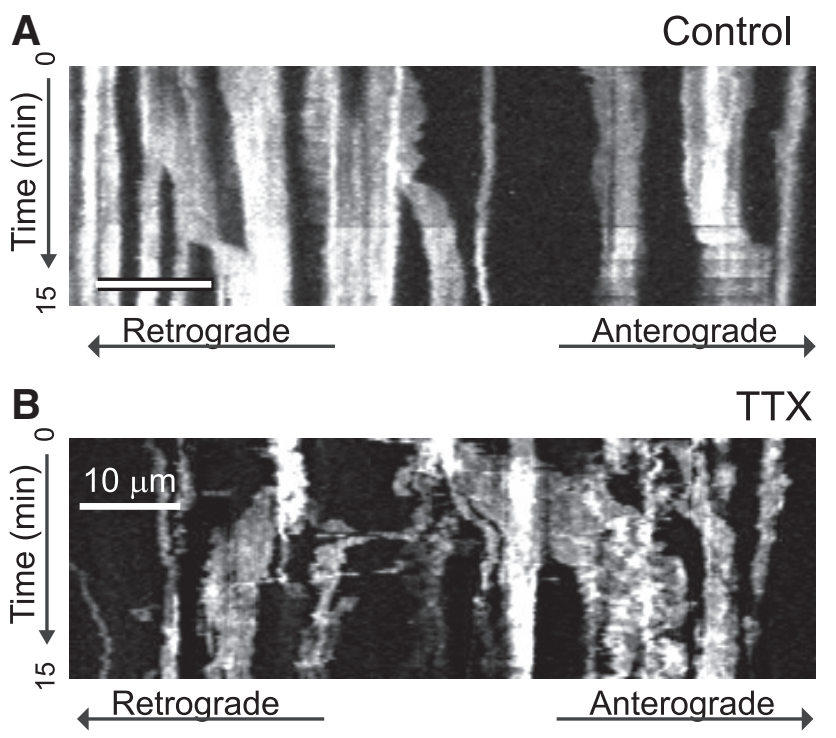

C

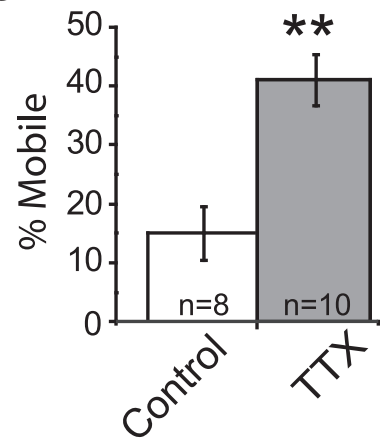

D

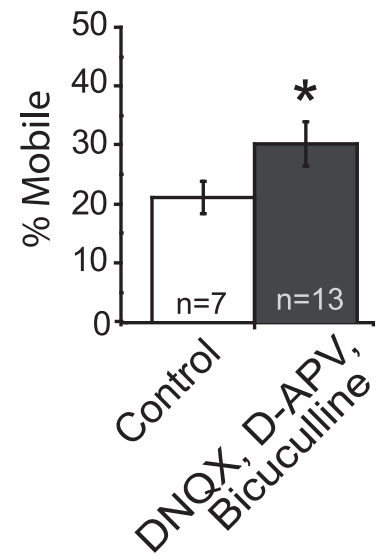

Figure 3. Inhibiting neuronal activity increases the percentage of mobile mitochondria in astrocytes. Slice cultures were continuously superfused with aCSF in the presence or absence of TTX (1 $\mu \mathrm{M})$ for a period of 15 min before imaging and throughout the imaging period. $\boldsymbol{A}, \boldsymbol{B}$, Kymographs show the movement of mitochondria along astrocyte processes in slices treated with control ( $\boldsymbol{A}$; aCSF) or TTX ( $\boldsymbol{B})$ over a $15 \mathrm{~min}$ period (time passes from top to bottom of image). Scale bar, $10 \mu \mathrm{m}$. $C$, The percentage of mobile mitochondria was calculated and is presented as the mean \pm SEM. $\boldsymbol{D}$, Histogram depicts the results of inhibiting ionotropic receptors. Slices were treated with APV $(50 \mu \mathrm{m})$, DNQX $(10 \mu \mathrm{m})$, and bicuculline (30 $\mu \mathrm{m})$ for $15 \mathrm{~min}$ before imaging and were continuously superfused with agents for imaging period. Results are mean \pm SEM. ${ }^{*} p<0.05 ;{ }^{* *} p<0.005$, unpaired Student's $t$ test.

trocytes, $44 \%$ of the mitochondria that were mobile moved in the retrograde direction (toward the cell body), while $56 \%$ moved in the anterograde direction. In neurons, $61 \%$ moved in the retrograde direction, while $39 \%$ moved in the anterograde direction. Since the movement was characterized by brief pauses accompanied by changes in speed and direction, we quantified the maximal instantaneous velocity of each mitochondrion. Neuronal mitochondria moved significantly farther (Fig. 2D) and faster (Fig. 2E) than did astrocytic mitochondria. The mean maximal velocity of mitochondrial movement in neurons was $0.55 \pm 0.05$ $\mu \mathrm{m} / \mathrm{s}(n=30)$ in the anterograde direction and $0.65 \pm 0.05 \mu \mathrm{m} / \mathrm{s}$ $(n=47)$ in the retrograde direction. Within astrocytes, the mean maximal velocity was $0.15 \pm 0.01 \mu \mathrm{m} / \mathrm{s}(n=47)$ in the anterograde direction and $0.2 \pm 0.02 \mu \mathrm{m} / \mathrm{s}(n=34)$ in the retrograde direction. These values are similar to those previously observed for the movement of mitochondria along actin filaments in sym- pathetic ganglia neurons (Morris and Hollenbeck, 1995). The lengths of individual mitochondria in astrocytes and neuronal dendrites, however, were similar (Fig. $2 F$ ).

Neuronal activity regulates the percentage of mobile mitochondria in astrocytes

In neurons, mitochondria are retained at sites of high activity and metabolic demand (Li et al., 2004; MacAskill et al., 2010; Ohno et al., 2011). Astrocytic activity and metabolism are highly integrated with neuronal activity. Therefore, we tested whether mitochondrial mobility in astrocytic processes was regulated by neuronal activity within the slice. Slices were pretreated for 15 min before imaging with TTX $(1 \mu \mathrm{M}), \mathrm{a} \mathrm{Na}^{+}$channel antagonist commonly used to decrease neuronal activity (Fig. 3). The percentage of mobile mitochondria in astrocytes increased $>3$-fold in TTX-treated slices compared with untreated controls (Fig. $3 C$ ). The relative ratio of astrocytic mitochondria moving in the anterograde versus retrograde directions changed from 2.6 in controls to 0.9 in TTX-treated slices. Inhibition of neuronal activity did not alter the velocity of mitochondrial movement or mitochondrial length (data not shown). Astrocytes in vivo and in situ express TTX-sensitive $\mathrm{Na}^{+}$channels (Sontheimer et al., 1994). Therefore, as an alternative approach to inhibit neuronal activity, we treated slices with inhibitors of NMDA (D-APV; 50 $\mu \mathrm{M}$ ), AMPA (DNQX; $10 \mu \mathrm{M}$ ), and GABA (bicuculline; $30 \mu \mathrm{M}$ ) receptors. Bicuculline was included, as GABA can be excitatory during the early postnatal period (Taketo and Yoshioka, 2000), before the developmental induction of the chloride pump KCC2 (Rivera, 1999). With this alternative method of blocking neuronal activity, the percentage of mobile mitochondria was again significantly higher in treated slices than in untreated controls (Fig. 3D). These results suggest that the mobility of mitochondria in astrocytes is influenced by neuronal activity.

\section{Mitochondrial movement depends on both microtubule and actin cytoskeleton}

Mitochondrial mobility in neurons depends on both the actin and microtubule cytoskeletons (Morris and Hollenbeck, 1995; Quintero et al., 2009). We examined the dependence of mitochondrial movement in TTX-treated slices in the presence and absence of inhibitors of microtubule (vinblastine) and actin (cytochalasin D) assembly (Fig. 4). All slices were pretreated with either TTX or aCSF for $15 \mathrm{~min}$. Slices were then treated with aCSF or TTX $(1 \mu \mathrm{M})$ in the presence or absence of vinblastine $(1 \mu \mathrm{g} / \mathrm{ml})$ or cytochalasin D $(20 \mu \mathrm{M})$ for an additional $15 \mathrm{~min}$ before imaging. No changes in cell viability or mitochondrial shape were observed following these treatments (data not shown). A greater percentage of mitochondria were mobile in slices treated with TTX than in untreated (aCSF) controls. Application of vinblastine or cytochalasin D decreased the percentage of mobile mitochondria relative to the TTX-treated slices. These results suggest that both the actin and microtubule cytoskeletons contribute to the movement of mitochondria in astrocytic processes.

\section{Mitochondrial mobility in astrocytes is not controlled by mGluR5 activation}

Astrocytes express a large complement of neurotransmitter receptors, including metabotropic glutamate receptors and purinergic receptors that allow them to sense and respond to neuronal activity (Newman, 2003). mGluR5 receptors in particular have been linked to increases in astrocytic $\mathrm{Ca}^{2+}$ concentration in response to neuronal activity (D'Ascenzo et al., 2007). We hypothesized that the activity-dependent decrease in mitochon- 
drial mobility in astrocytes might be secondary to activation of mGluR5 receptors. Slices were treated with the mGluR5 antagonist MPEP $(5 \mu \mathrm{M})$ for $15 \mathrm{~min}$ before imaging. Inhibition of mGluR 5 did not change the percentage of mitochondria that were mobile relative to untreated controls $(13 \pm 3 \%, n=12$, vs $13 \pm 2 \%$, $n=9)$. In another set of experiments, we asked whether activation of mGluR5 receptors is sufficient to decrease mitochondrial mobility. Slices were pretreated with TTX $(1 \mu \mathrm{M})$ before the addition of DHPG $(50 \mu \mathrm{M})$. Addition of the mGluR5 agonist did not significantly decrease the TTXinduced increase in mitochondrial mobility ( $45 \pm 7 \%, n=4$, vs $36 \pm 8 \%, n=6)$. Together, these results suggest that mitochondrial mobility in astrocytes is not controlled by mGluR5 activation.

\section{Glutamate transport regulates the percentage of mobile mitochondria in astrocytes}

Synaptic glutamate concentrations are kept low $(\sim 25 \mathrm{~nm})$ via the actions of the $\mathrm{Na}^{+}$-dependent glutamate transporters in astrocytes, particularly GLT-1 and glutamate-aspartate transporter (GLAST; Herman and Jahr, 2007). Glutamate transporter activity results in the activation of the $\mathrm{Na}^{+} / \mathrm{K}^{+}$-ATPase, glycolysis (Pellerin and Magistretti, 1994), and oxidative phosphorylation (Loaiza et al., 2003). We tested whether glutamate uptake influenced mitochondrial mobility in astrocytes by inhibiting glutamate uptake with TFB-TBOA ( $3 \mu \mathrm{M}$; Shimamoto et al., 2004). Similar to the effects of TTX, inhibition of glutamate uptake resulted in a $>3$-fold increase in the percentage of mitochondria that were mobile relative to untreated controls (Fig. 5C). Treatment with TFB-TBOA did not alter either the rate of mitochondrial movement (Fig. $5 D$ ) or the proportion of mitochondria moving in the anterograde versus retrograde directions. We also asked whether activation of the transporters is sufficient to decrease mitochondrial mobility. We inhibited neuronal activity with TTX (1 $\mu \mathrm{M} ; 15 \mathrm{~min}$ ) before addition of the transporter substrate D-aspartate (1 or $10 \mathrm{~mm}$ ). Treatment with TTX (Fig. 5E) increased the percentage of mitochondria that were mobile relative to untreated controls. Application of D-aspartate to TTX-treated slices decreased the percentage of mitochondria that were mobile in a concentration-dependent manner relative to TTX-treated controls (Fig. 5E). Combined, these results demonstrate that glutamate (aspartate) uptake into astrocytes regulates the mobility of mitochondria in astrocytes.

Glutamate transport results in a significant increase in intracellular $\left[\mathrm{Na}^{+}\right]$(Rose and Ransom, 1996) and stimulates
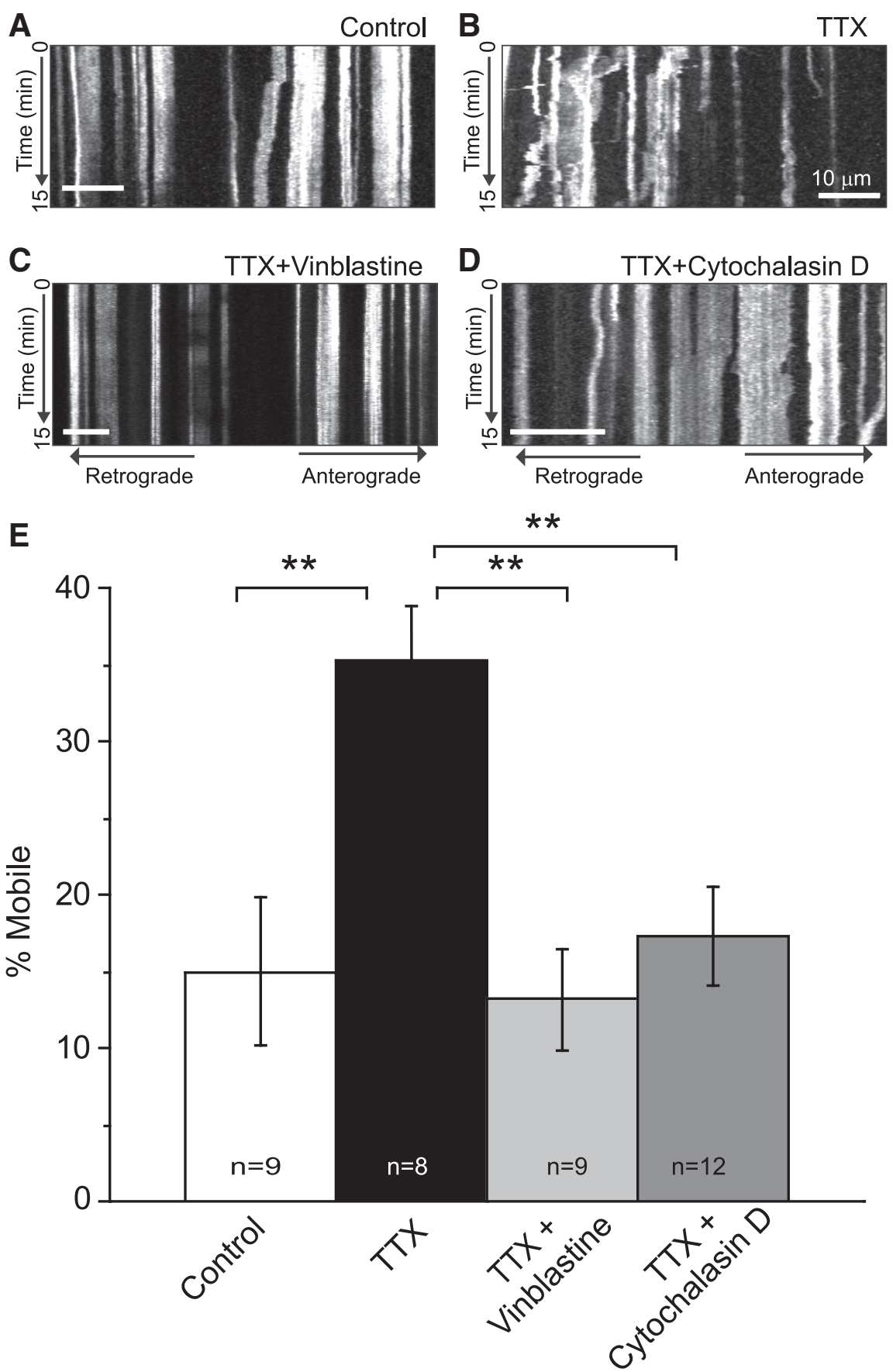

Figure 4. Mitochondrial mobility depends on both the actin and microtubule cytoskeletons. $A-D$, Kymographs depict the movement of mitochondria along astrocyte processes in slices treated with vehicle $(\boldsymbol{A} ; \mathrm{aCSF}), \operatorname{TTX}(\boldsymbol{B} ; 1 \mu \mathrm{M}), \operatorname{TTX}$ plus vinblastine $(\boldsymbol{C}$; $1 \mu \mathrm{g} / \mathrm{ml})$, or TTX plus cytochalasin D $(\boldsymbol{D} ; 20 \mu \mathrm{m})$. Slices were continuously superfused with aCSF or TTX for $15 \mathrm{~min}$ before the application of vinblastine $(1 \mu \mathrm{g} / \mathrm{ml})$ or cytochalasin $\mathrm{D}(20 \mu \mathrm{m})$. Slices were continuously superfused with these compounds (in the continued presence of TTX) for an additional $15 \mathrm{~min}$ before the initiation of confocal imaging. Treatments were continued for the entire imaging period. The percentage of mobile mitochondria in astrocytes was determined over a 15 min imaging epoch. $\boldsymbol{E}$, Results are presented as mean \pm SEM. ${ }^{* *} p<0.005$ by ANOVA with Bonferonni's multiple-comparison test.

$\mathrm{Na}^{+} / \mathrm{K}^{+}$-ATPase activity (Pellerin and Magistretti, 1994). It is unsurprising, therefore, that the $\mathrm{Na}^{+} / \mathrm{K}^{+}$-ATPase physically interacts with both GLT-1 and GLAST (Rose et al., 2009; Genda et al., 2011). Activation of $\mathrm{Na}^{+} / \mathrm{K}^{+}$-ATPase decreases mitochondrial mobility at the nodes of Ranvier in sciatic nerves (Zhang et al., 2010). Given this, we tested whether an inhibitor of $\mathrm{Na}^{+} / \mathrm{K}^{+}$-ATPase activity (ouabain) would influence mitochondrial mobility in astrocytes. Astrocytes possess 
A
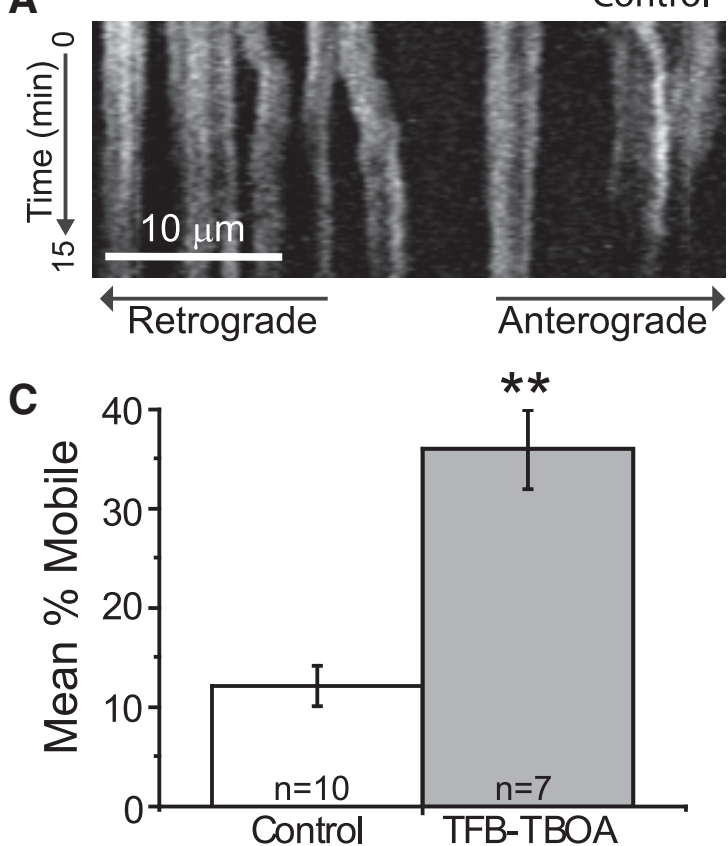

E
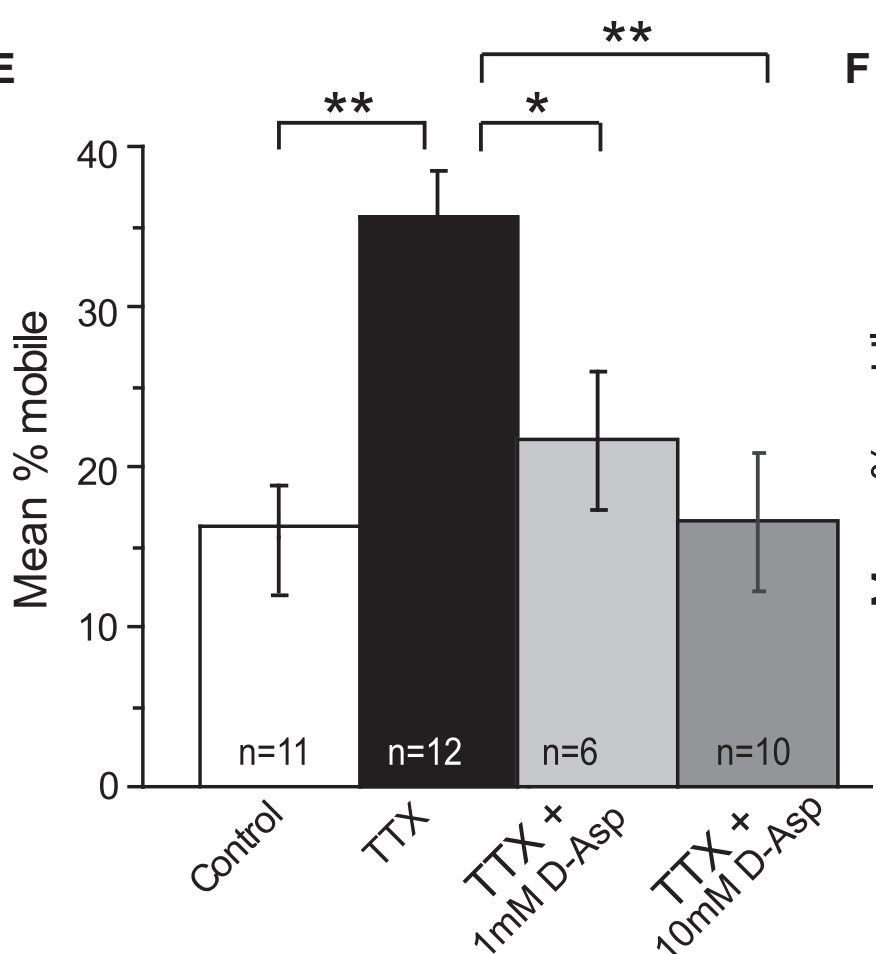

B

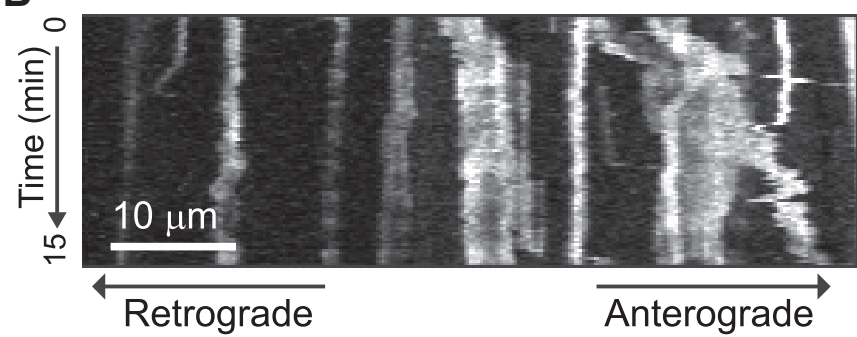

D
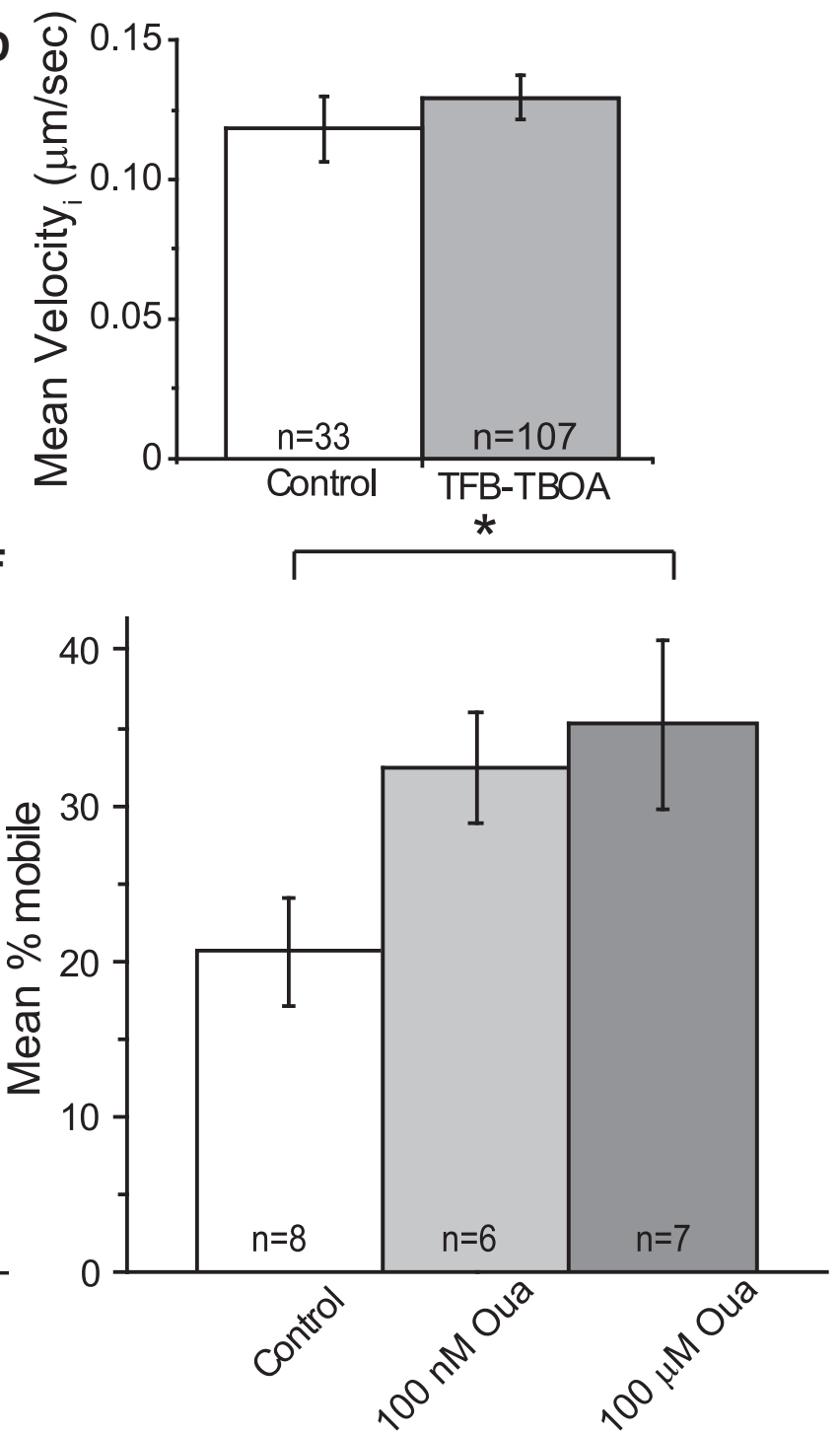

Figure 5. Glutamate transport and $\mathrm{Na}^{+} / \mathrm{K}^{+}$-ATPase activation regulate mitochondrial mobility in astrocytes. Astrocytes in slice culture were transfected with EGFP-mito and GFA $A_{\mathrm{ABC} 1 D^{-}} \mathrm{mCherry}$ at 2 DIV and imaged at 4 DIV. $A-E$, Slices were continuously superfused with aCSF in the presence or absence of TFB-TBOA $(3 \mu \mathrm{M})$ for 15 min before the initiation of imaging and throughout the imaging period. $\boldsymbol{A}, \boldsymbol{B}$, Representative kymographs show the movement of mitochondria in astrocytes in aCSF-treated $(\boldsymbol{A})$ and TFB-TBOA-treated $(\boldsymbol{B})$ slices over a $15 \mathrm{~min}$ period (time passes from top to bottom of image). In these kymographs, stationary mitochondria are seen as straight lines and moving mitochondria as diagonal lines. Scale bar, $10 \mu \mathrm{m}$. $C$, Histogram shows the mean percentage of mitochondria that were mobile. ${ }^{* *} p<0.005$ by unpaired Student's $t$ test. $\boldsymbol{D}$, Histogram depicts the mean maximal instantaneous velocity of individual astrocytic mitochondria in control (open) and TFB-TBOA-treated (gray) slices. $\boldsymbol{E}$, Histogram depicts the effect of treatment with TTX in the presence or absence of D-aspartate on the percentage of mobile mitochondria. Slices were treated with aCSF in the presence or absence of TTX for $15 \mathrm{~min}$, at which point D-aspartate (1 or $10 \mathrm{~mm}$ ) was applied to TTX-treated slices. $F$, Histogram depicts the effects of ouabain (100 nm or $100 \mu \mathrm{M}$ ) on the percentage of mobile mitochondria in astrocytes. Results are mean $\pm \mathrm{SEM} .{ }^{*} p<0.05 ;{ }^{* *} p<0.005$ by ANOVA with Bonferroni's multiple-comparisons test.

two isoforms of the $\mathrm{Na}^{+} / \mathrm{K}^{+}$-ATPase $\alpha$ subunits $(\alpha 1$ and $\alpha 2$; Juhaszova and Blaustein, 1997). These subunits possess different sensitivities to ouabain: $\alpha 2$ is inhibited at nanomolar concentrations, while the $\alpha 1$ isoform is inhibited at concentrations $>10 \mu \mathrm{M}$ (Juhaszova and Blaustein, 1997; Pellerin and
Magistretti, 1997). We treated slice cultures with either $100 \mathrm{~nm}$ or $100 \mu \mathrm{M}$ ouabain for $15 \mathrm{~min}$ before the start of imaging. Treatment with $100 \mu \mathrm{M}$ ouabain resulted in a significant increase in the percentage of mitochondria that were mobile in astrocytes (Fig. $5 F$ ). 
Reversed $\mathrm{Na}^{+} / \mathrm{Ca}^{2+}$ exchange regulates mitochondrial mobility

The bidirectional $\mathrm{Na}^{+} / \mathrm{Ca}^{2+}$ exchanger (NCX) normally couples the inward movement of three $\mathrm{Na}^{+}$ions to the outward movement of one $\mathrm{Ca}^{2+}$ ion (Blaustein and Lederer, 1999). In astrocytes, activation of glutamate transport activates the reverse mode of the NCX subsequent to $\mathrm{Na}^{+}$entry, resulting in an increase in intracellular $\left[\mathrm{Ca}^{2+}\right]$ (Magi et al., 2013; Rojas et al., 2013). We tested the hypothesis that reversal of the NCX contributes to immobilization of mitochondria in astrocytes. We treated hippocampal slice cultures with two structurally dissimilar inhibitors of the reverse mode of the NCX $\left(\mathrm{Na}^{+}\right.$efflux/ $\mathrm{Ca}^{2+}$ influx) for $15 \mathrm{~min}$ before the start of imaging. At concentrations that selectively block the reversed mode operation of NCX, while minimally affecting normal inward flux of $\mathrm{Na}^{+}, \mathrm{KB}-\mathrm{R} 7943(15 \mu \mathrm{M})$ or YM-244769 (1 $\mu \mathrm{M})$ increased the percentage of mitochondria that were mobile within the processes of astrocytes to a similar degree to TTX ( $1 \mu \mathrm{M}$; positive control; Fig. 6). While KB-7943 also blocks NMDA receptors and inhibits complex 1 of the mitochondrial electron transport chain, no such off-target effects have been reported for YM-244769 (Brustovetsky et al., 2011; Clerc and Polster, 2012). Thus, these results suggest that tonic activation of the reverse mode of the NCX is contributing to mitochondrial immobilization in astrocytes.

\section{Association of mitochondria with glutamate transporters}

In neurons, the positioning of mitochondria at sites of heightened energy use (presynaptic termini, postsynaptic spines, or nodes of Ranvier) or elevated $\left[\mathrm{Ca}^{2+}\right]$ is critical to maintain energy and $\mathrm{Ca}^{2+}$ homeostasis. We tested whether the neuronal activity-induced decreases in mitochondrial mobility in astrocytes were correlated with the positioning/retention of mitochondria near glutamate transporters (GLT-1), where demand would be predicted to be elevated. Slices cotransfected with $\mathrm{GFA}_{\mathrm{ABC} 1 \mathrm{D}}$-mCherry (Fig. 7A) and EGFP-mito (Fig. 7B) were treated with TTX (1 $\mu \mathrm{M})$ or vehicle for $30 \mathrm{~min}$. Slices were subsequently immunostained for VGLUT1 (Fig. 7C) and GLT-1 (Fig. 7D). mCherry fluorescence was used to construct a digital mask allowing for the identification of GLT-1 puncta within individual astrocyte processes. In an earlier study, we examined the overlap between mitochondria and exogenously expressed GLT-1 tagged with a fluorescent epitope using the same system, except that slices were not incubated with aCSF for $30 \mathrm{~min}$ at $34^{\circ} \mathrm{C}$ (Genda et al., 2011). As this approach results in overexpression of transporter that could in-
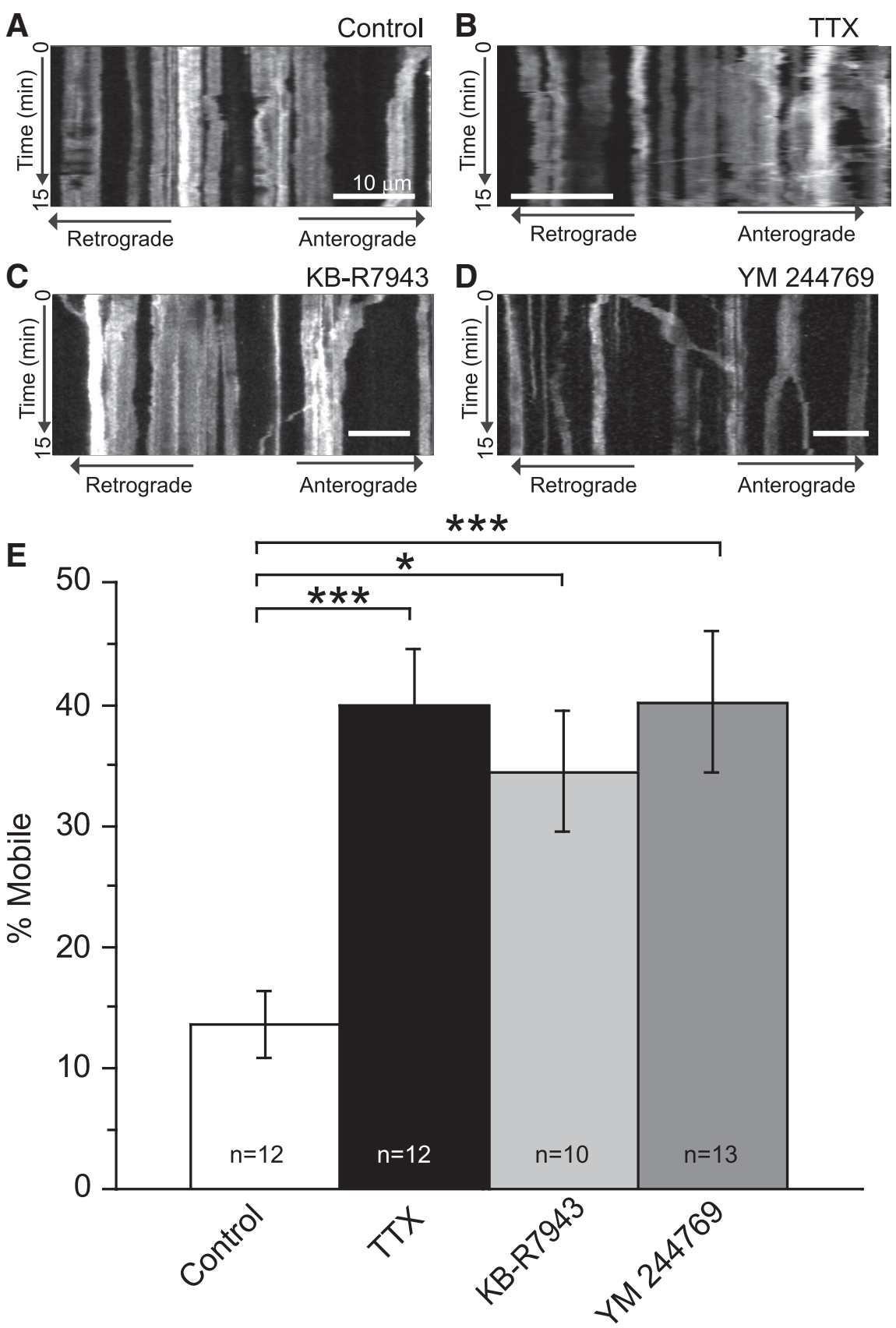

Figure 6. Mitochondrial mobility in astrocytes is increased by inhibition of the reverse-mode operation of the $\mathrm{Na}^{+} / \mathrm{Ca}^{2+}$ exchanger. A-D, Slices were continuously superfused with aCSF in the presence or absence of TTX (1 $\mu \mathrm{M}), \mathrm{KB}-\mathrm{R} 7943$ (15 $\mu \mathrm{M})$, or YM-244769 $(1 \mu \mathrm{M})$ for 15 min before the initiation of imaging and throughout the imaging period. Representative kymographs show the movement of mitochondria in astrocytes treated with aCSF $(\boldsymbol{A}), \operatorname{TTX}(\boldsymbol{B}), \mathrm{KB}-\mathrm{R7943}$ (C), or YM-244769 (D) over a 15 min period (time passes from top to bottom of image). In these kymographs, stationary mitochondria are seen as straight lines and moving mitochondria as diagonal lines. Scale bar, $10 \mu \mathrm{m}$. $\boldsymbol{E}$, Histogram depicts the percentage of mitochondria that were mobile following treatment. Results are mean \pm SEM. ${ }^{*} p<0.05 ;{ }^{* * *} p<0.005$ by ANOVA with Bonferroni's multiple-comparisons test.

fluence the extent of overlap between GLT-1 puncta and mitochondria, we first examined overlap of endogenous GLT-1 with mitochondria. We found that $38 \pm 6 \%$ of GLT-1 puncta were overlapped by a mitochondria and $64 \pm 7 \%$ of mitochondria were overlapped by GLT-1. These values are somewhat lower than those observed in the earlier study, but are indicative of substantial overlap between GLT-1 and mitochondria under these conditions. These images were also used to compare the anatomic relationship of GLT-1 puncta, mitochondria, and synapses (VGLUT+) in the presence and absence of TTX (Fig. 7E). 

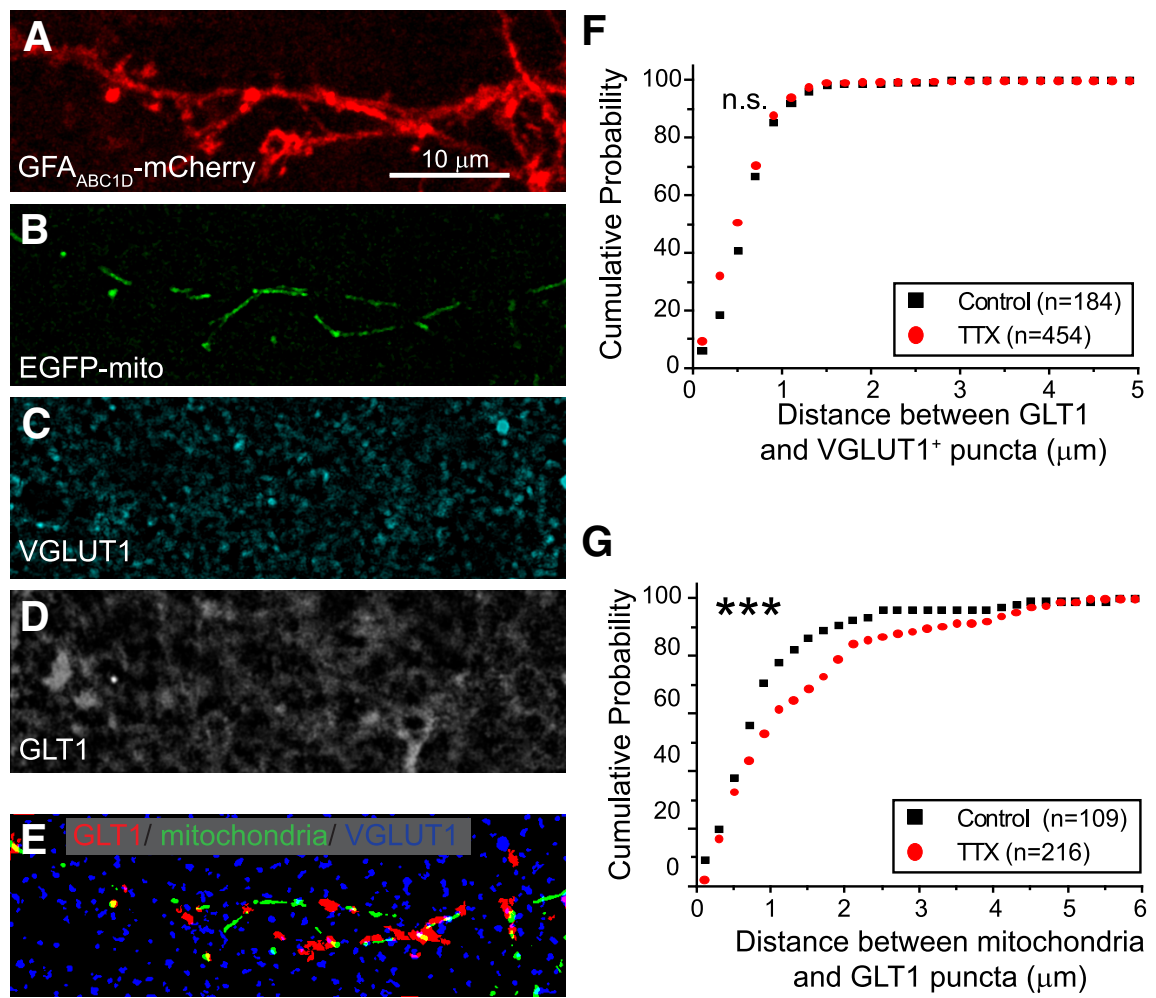

Figure 7. Neuronal activity increases the probability that mitochondria appose GLT-1 in astrocytic processes without affecting the relationship of GLT-1 to VGLUT1. Astrocytes were transfected with plasmids encoding EGFP-mito and a membrane-targeted $\mathrm{mCherry}$ fluorescent protein. Slices were treated in the absence or presence of TTX $(1 \mu \mathrm{M})$ for $30 \mathrm{~min}$. Slices were fixed and subsequently immunostained with antibodies against VGLUT1 and GLT-1. $\boldsymbol{A}-\boldsymbol{D}$, Representative images of an astrocyte process expressing $\mathrm{GFA}_{\mathrm{ABC1D}}$-mCherry $(\boldsymbol{A})$, and EGFP-mito $(\boldsymbol{B})$, and immunostained for VGLUT1 (C) and GLT-1 (D). $\boldsymbol{E}$, Representative image depicting GLT-1 (red), mitochondria (green), and VGLUT1+ (blue) puncta from the process depicted in $\boldsymbol{A}-\boldsymbol{D}$. F, G, Cumulative probability distributions depicting the distance between each GLT-1 and the nearest VGLUT1 + $(\boldsymbol{F})$ puncta and between each mitochondrion and the nearest GLT- 1 puncta $(\boldsymbol{G})$ in the absence (black boxes) and presence (red circles) of TTX. ${ }^{* * *} p<0.0001$ by Kolmogorov-Smirnov test.

The minimum distance between the centers of GLT-1 puncta and VGLUT1 (Fig. $7 F$ ) and between mitochondria and GLT-1 puncta (Fig. $7 G$ ) was measured and expressed as a cumulative probability distribution. Interestingly, reducing neuronal activity (TTX) did not change the relationship between GLT-1+ and VGLUT1+ puncta, suggesting that GLT-1 remains near synapses in the presence of TTX. However, reducing neuronal activity decreased the probability (evident as a rightward shift in the cumulative distribution) that mitochondria approach a GLT-1 puncta (i.e., increased distance), suggesting that neuronal activity regulates the position of mitochondria relative to GLT-1 $(p<0.0001)$. As mitochondria are quite long relative to the distances being measured, we also examined the relationship between the edges of mitochondria and GLT-1 puncta, as any overlap would presumably allow for functional coupling between transporters and mitochondria. As was observed using the centers of the particles, the cumulative probably plot revealed a significant difference in the presence and absence of TTX $(p=0.02)$. In the presence of TTX, there was greater likelihood that mitochondria were farther from GLT-1 puncta (data not shown).

\section{Discussion}

In neurons, mitochondria accumulate at sites of high activity and energetic demand, including presynaptic and postsynaptic terminals (Li et al., 2004; Miller and Sheetz, 2004), growth cones (Morris and Hollenbeck, 1993), and nodes of Ranvier (Ohno et al.,
2011), where they provide local energetic support and regulate ionic homeostasis (for review, see Schwarz, 2013). Mitochondria have been localized within the processes of astrocytes (Lovatt et al., 2007; Ito et al., 2009; Lavialle et al., 2011) in close proximity to glutamate transporters (Chaudhry et al., 1995; Genda et al., 2011). Here we describe the mobility of mitochondria within the processes of astrocytes. In addition, we describe a potential mechanism by which glutamate release from neurons is converted to mitochondrial immobilization in astrocytes via glutamate uptake through the astrocytic glutamate transporters, and reversed $\mathrm{Na}^{+} / \mathrm{Ca}^{2+}$ exchange. Further, we show that neuronal activity is associated with an increased probability that mitochondria approach glutamate transporter clusters in the processes of astrocytes without changing the relationship of GLT-1 puncta to VGLUT1 (synapses). Together, this work suggests a mechanism by which mitochondria may be recruited to, or retained at, areas of high GLT-1 expression that surround synapses.

\section{Mitochondria in astrocyte processes}

We used time-lapse imaging of mitochondria to examine mitochondrial movement in neuronal and astrocytic processes. While mitochondria in neurons and astrocytes displayed similar lengths, there were significant differences with regard to rate of movement and the fraction mobile. Our findings in neurons are similar to that which has been observed (fraction mobile, velocity, and size; for review, see MacAskill et al., 2010). The difference between astrocytic and neuronal mitochondrial movement suggests that mitochondrial mobility in astrocytes might be regulated by different motor proteins or move along different cytoskeletal elements. Indeed, the rates of movement observed in astrocytes match those observed for short-range mitochondrial transport along actin filaments (Morris and Hollenbeck, 1995).

In neurons, mitochondrial mobility has been linked to both the actin and microtubule cytoskeleton. Long-range mitochondrial movement in neurons depends on transport by kinesins (anterograde) and dynein (retrograde) motors along the microtubule cytoskeleton (for review, see Schwarz, 2013). Short-range movement along actin fibers has been described (Morris and Hollenbeck, 1995; Ligon and Steward, 2000; Hollenbeck, 2005). We examined the movement of mitochondria in response to treatment with inhibitors of actin and microtubule assembly. Our results suggest that, in astrocytes (as in neurons), mitochondrial movement depends on both the actin and microtubule cytoskeleton. It will be interesting to identify the motor proteins involved. Anterograde transport along microtubules in neurons is mediated primarily by the kinesin isoforms Kif5 and Kif1B (MacAskill and Kittler, 2010). The major kinesin isoforms in astrocytes have yet to be determined. However, KIF5A and C are thought to be neuron-specific motor proteins (Kanai et al., 2000). 


\section{Retention of mitochondria by neuronal activity}

Why move mitochondria? The coordinated transport of mitochondria along cellular processes likely serves several functions. First, movement of mitochondria appears necessary for the distribution of mitochondria into cellular processes. Mitochondria are primarily generated in the cell body and are transported in an anterograde direction into the processes (for review, see Schwarz, 2013). Conversely, the observation that depolarized mitochondria move primarily in the retrograde direction has been used to suggest that dysfunctional mitochondria move toward the cell body for repair/degradation (Frederick and Shaw, 2007). Second, movement of mitochondria facilitates the processes of fusion and fission that allow the exchange of proteins and genetic material between discreet mitochondria (Misko et al., 2010). Last, mitochondrial transport provides a mechanism for the redistribution of mitochondria to sites of high activity (for review, see MacAskill and Kittler, 2010; Schwarz, 2013).

In neurons, mitochondria are retained at sites of high activity and metabolic demand (Li et al., 2004; Wang and Schwarz, 2009; Ohno et al., 2011). Neuronal activity and glutamate receptor activation decrease mitochondrial mobility and cause mitochondria to pause at synapses and at nodes of Ranvier in neurons. Astrocytes sense neuronal activity (Halassa et al., 2007a), and much of their activity is devoted to processes, such as glutamate uptake, that are integrated with neuronal activity (Parpura and Verkhratsky, 2012). We hypothesized that neuronal activity might influence mitochondrial movement within astrocytic processes. Inhibition of neuronal activity with TTX or ionotropic receptor antagonists increased the percentage of mitochondria that were mobile in astrocytes. While astrocytes in vitro and in situ express multiple isoforms of the voltage-dependent $\mathrm{Na}^{+}$channel family (Sontheimer et al., 1994), the observation that inhibition of ionotropic receptors (NMDA, AMPA, and GABA receptors) also increased mitochondrial mobility suggests that this effect is mediated by neurons. Additionally, our results also indicate that the increased mobility of mitochondria in TTX-treated slices is blocked by application of the transporter substrate D-aspartate (Fig. 5). Together, these results strongly suggest that mitochondrial mobility in astrocytes is regulated by neuronal activity.

Astrocytes are the primary route of clearance for extracellular glutamate (Danbolt, 2001). Glutamate transport and concomitant activation of the $\mathrm{Na}^{+} / \mathrm{K}^{+}$-ATPase represent a substantial energetic demand on astrocytes (Hertz et al., 2007). We hypothesized that glutamate uptake might influence astrocytic mitochondrial mobility. Our results suggest that neuronal activity regulates astrocytic mitochondrial mobility via activation of glutamate transporters. It remains to be determined whether this immobilization is a result of the glutamate transport cycle, or is subsequent to another process, such as activation of the $\mathrm{Na}^{+}$/ $\mathrm{K}^{+}$-ATPase. Although inhibition of the $\mathrm{Na}^{+} / \mathrm{K}^{+}$-ATPase increased the percentage of mitochondria that were mobile in astrocytes (Fig. 5G), there are at least three possible explanations for this result. First, it is possible the effects of ouabain are related to the spreading depression that ouabain induces via the neuronal $\mathrm{Na}^{+} / \mathrm{K}^{+}$-ATPase isoforms (Balestrino et al., 1999). Second, ouabain is also known to inhibit glutamate uptake (Li and Stys, 2001; Rose et al., 2009). Finally, it is possible that activation of the $\mathrm{Na}^{+} / \mathrm{K}^{+}$ATPase is required for mitochondrial immobilization in astrocytes. Although Zhang et al., 2010 favored this later mechanism to explain docking of mitochondria near nodes of Ranvier, we cannot discriminate between these possibilities in the current study.

Several mechanisms contribute to the immobilization of mitochondria in neurons in response to increased activity. Increases in $[\mathrm{ADP}]$ result in decreased mitochondrial transport (Mironov, 2007). Additionally, increases in intracellular $\left[\mathrm{Ca}^{2+}\right]$ subsequent to NMDAR activation stop mitochondria at the base of dendritic spines (Li et al., 2004; Wang and Schwarz, 2009). As increases in neuronal activity activate mGluR5 receptors in astrocytes (D'Ascenzo et al., 2007), we tested whether activation of mGluR5 contributed to the neuronal activity-dependent immobilization of mitochondria in astrocytes. Surprisingly, neither activation nor inhibition of mGluR5 altered mitochondrial mobility. However, selective inhibition of the reverse mode of $\mathrm{Na}^{+} / \mathrm{Ca}^{2+} \mathrm{ex}^{-}$ change increased the percentage of mobile mitochondria, suggesting that increases in $\left[\mathrm{Ca}^{2+}\right]_{\mathrm{i}}$ via the NCX might contribute to the immobilization of mitochondria in astrocytes.

Why move mitochondria to sites of glutamate transport? Mitochondria play important roles in a variety of processes, including ATP production, ionic buffering, and glutamate oxidation. Glutamate uptake has been coupled to all three of these processes. For example, glutamate uptake increases astrocytic glycogen utilization (Swanson, 1992), glycolysis (Pellerin and Magistretti, 1994), and oxygen consumption (Eriksson et al., 1995). Glutamate uptake is coupled to an increase in mitochondrial $\mathrm{Na}^{+}$ concentration (Bernardinelli et al., 2006) and is accompanied by rapid mitochondrial acidification (Azarias et al., 2011). These studies imply that mitochondria buffer the ionic changes associated with transporter function. Mitochondria also play a critical role in glutamate metabolism (for review, see Dienel, 2013). Upon import into astrocytes, glutamate can either be converted to glutamine via glutamine synthetase or oxidized to mitochondrial TCA cycle intermediates (Yudkoff et al., 1988). In brain, most glutamate oxidation is thought to occur in astrocytes (Hertz et al., 1988; Waagepetersen et al., 2002). In fact, the fraction of glutamate that is oxidized increases disproportionately with increasing extracellular glutamate (Yu et al., 1982; McKenna et al., 1996). The oxidation of glutamate by mitochondria may fuel glutamate uptake by providing the ATP necessary for $\mathrm{Na}^{+}$extrusion (Peng et al., 2001; Whitelaw and Robinson, 2013; for review, see Dienel, 2013). All of these functions would be supported by the immobilization of mitochondria near sites of glutamate uptake. The development of tools to selectively block the docking of mitochondria in astrocytes will be necessary to test the functional significance of mitochondrial immobilization.

Here, we provide the first description of mitochondrial mobility in the processes of astrocytes. Mitochondrial mobility is regulated by neuronal activity, glutamate transport, and $\mathrm{Na}^{+} / \mathrm{Ca}^{2+}$ exchange. Further, neuronal activity regulates the retention/accumulation of mitochondria at sites enriched in glutamate transporters that are apposed to synapses. The transport of mitochondria within astrocytes likely influences, and is influenced by, other aspects of astrocyte biology. Future experiments will be necessary to examine whether other processes influence mitochondrial function in astrocytes, to determine which motors are responsible for their movement, and to find answers to why and how the mitochondria are kept stationary.

\section{References}

Azarias G, Perreten H, Lengacher S, Poburko D, Demaurex N, Magistretti PJ, Chatton JY (2011) Glutamate transport decreases mitochondrial pH and modulates oxidative metabolism in astrocytes. J Neurosci 31:35503559. CrossRef Medline

Balestrino M, Young J, Aitken P (1999) Block of (Na+, K+)ATPase with ouabain induces spreading depression-like depolarization in hippocampal slices. Brain Res 838:37-44. CrossRef Medline

Bauer DE, Jackson JG, Genda EN, Montoya MM, Yudkoff M, Robinson MB (2012) The glutamate transporter, GLAST, participates in a macromo- 
lecular complex that supports glutamate metabolism. Neurochem Int 61:566-574. CrossRef Medline

Benediktsson AM, Schachtele SJ, Green SH, Dailey ME (2005) Ballistic labeling and dynamic imaging of astrocytes in organotypic hippocampal slice cultures. J Neurosci Methods 141:41-53. CrossRef Medline

Bergles DE, Jahr CE (1997) Synaptic activation of glutamate transporters in hippocampal astrocytes. Neuron 19:1297-1308. CrossRef Medline

Bernardinelli Y, Azarias G, Chatton JY (2006) In situ fluorescence imaging of glutamate-evoked mitochondrial $\mathrm{Na}+$ responses in astrocytes. Glia 54:460-470. CrossRef Medline

Blaustein MP, Lederer WJ (1999) Sodium/calcium exchange: its physiological implications. Physiol Rev 79:763-854. Medline

Brustovetsky T, Brittain MK, Sheets PL, Cummins TR, Pinelis V, Brustovetsky N (2011) KB-R7943, an inhibitor of the reverse $\mathrm{Na}+/ \mathrm{Ca} 2+$ exchanger, blocks N-methyl-D-aspartate receptor and inhibits mitochondrial complex I. Br J Pharmacol 162:255-270. CrossRef Medline

Cai Q, Sheng ZH (2009) Mitochondrial transport and docking in axons. Exp Neurol 218:257-267. CrossRef Medline

Chaudhry FA, Lehre KP, van Lookeren Campagne M, Ottersen OP, Danbolt NC, Storm-Mathisen J (1995) Glutamate transporters in glial plasma membranes: highly differentiated localizations revealed by quantitative ultrastructural immunocytochemistry. Neuron 15:711-720. CrossRef Medline

Choi DW (1992) Excitotoxic cell death. J Neurobiol 23:1261-1276. CrossRef Medline

Clerc P, Polster BM (2012) Investigation of mitochondrial dysfunction by sequential microplate-based respiration measurements from intact and permeabilized neurons. PLoS One 7:e34465. CrossRef Medline

Conti F, Weinberg RJ (1999) Shaping excitation at glutamatergic synapses. Trends Neurosci 22:451-458. CrossRef Medline

Danbolt NC (2001) Glutamate uptake. Prog Neurobiol 65:1-105. CrossRef Medline

D’Ascenzo M, Fellin T, Terunuma M, Revilla-Sanchez R, Meaney DF, Auberson YP, Moss SJ, Haydon PG (2007) mGluR5 stimulates gliotransmission in the nucleus accumbens. Proc Natl Acad Sci U S A 104:1995-2000. CrossRef Medline

Dienel GA (2013) Astrocytic energetics during excitatory neurotransmission: what are contributions of glutamate oxidation and glycolysis? Neurochem Int 63:244-258. CrossRef Medline

Eriksson G, Peterson A, Iverfeldt K, Walum E (1995) Sodium-dependent glutamate uptake as an activator of oxidative metabolism in primary astrocyte cultures from newborn rat. Glia 15:152-156. CrossRef Medline

Frederick RL, Shaw JM (2007) Moving mitochondria: establishing distribution of an essential organelle. Traffic 8:1668-1675. CrossRef Medline

Genda EN, Jackson JG, Sheldon AL, Locke SF, Greco TM, O’Donnell JC, Spruce LA, Xiao R, Guo W, Putt M, Seeholzer S, Ischiropoulos H, Robinson MB (2011) Co-compartmentalization of the astroglial glutamate transporter, GLT-1, with glycolytic enzymes and mitochondria. J Neurosci 31:18275-18288. CrossRef Medline

Halassa MM, Fellin T, Haydon PG (2007a) The tripartite synapse: roles for gliotransmission in health and disease. Trends Mol Med 13:54-63. CrossRef Medline

Halassa MM, Fellin T, Takano H, Dong JH, Haydon PG (2007b) Synaptic islands defined by the territory of a single astrocyte. J Neurosci 27:64736477. CrossRef Medline

Herman MA, Jahr CE (2007) Extracellular glutamate concentration in hippocampal slice. J Neurosci 27:9736-9741. CrossRef Medline

Hertz L, Drejer J, Schousboe A (1988) Energy metabolism in glutamatergic neurons, GABAergic neurons and astrocytes in primary cultures. Neurochem Res 13:605-610. CrossRef Medline

Hertz L, Peng L, Dienel GA (2007) Energy metabolism in astrocytes: high rate of oxidative metabolism and spatiotemporal dependence on glycolysis/glycogenolysis. J Cereb Blood Flow Metab 27:219-249. CrossRef Medline

Hollenbeck PJ (2005) Mitochondria and neurotransmission: evacuating the synapse. Neuron 47:331-333. CrossRef Medline

Ito U, Hakamata Y, Kawakami E, Oyanagi K (2009) Degeneration of astrocytic processes and their mitochondria in cerebral cortical regions peripheral to the cortical infarction: heterogeneity of their disintegration is closely associated with disseminated selective neuronal necrosis and maturation of injury. Stroke 40:2173-2181. CrossRef Medline

Juhaszova M, Blaustein MP (1997) Na+ pump low and high ouabain affin- ity alpha subunit isoforms are differently distributed in cells. Proc Natl Acad Sci U S A 94:1800-1805. CrossRef Medline

Kanai Y, Okada Y, Tanaka Y, Harada A, Terada S, Hirokawa N (2000) KIF5C, a novel neuronal kinesin enriched in motor neurons. J Neurosci 20:6374-6384. Medline

Kayser MS, McClelland AC, Hughes EG, Dalva MB (2006) Intracellular and trans-synaptic regulation of glutamatergc synaptogenesis by EphB receptors. J Neurosci 26:12152-12164. CrossRef Medline

Lavialle M, Aumann G, Anlauf E, Pröls F, Arpin M, Derouiche A (2011) Structural plasticity of perisynaptic astrocyte processes involves ezrin and metabotropic glutamate receptors. Proc Natl Acad Sci U S A 108:1291512919. CrossRef Medline

Lee Y, Messing A, Su M, Brenner M (2008) GFAP promoter elements required for region-specific and astrocyte-specific expression. Glia 56:481493. CrossRef Medline

Li S, Stys PK (2001) $\mathrm{Na}(+)-\mathrm{K}(+)$-ATPase inhibition and depolarization induce glutamate release via reverse $\mathrm{Na}(+)$-dependent transport in spinal cord white matter. Neuroscience 107:675-683. CrossRef Medline

Li Z, Okamoto K, Hayashi Y, Sheng M (2004) The importance of dendritic mitochondria in the morphogenesis and plasticity of spines and synapses. Cell 119:873-887. CrossRef Medline

Ligon LA, Steward O (2000) Role of microtubules and actin filaments in the movement of mitochondria in the axons and dendrites of cultured hippocampal neurons. J Comp Neurol 427:351-361. CrossRef Medline

Loaiza A, Porras OH, Barros LF (2003) Glutamate triggers rapid glucose transport stimulation in astrocytes as evidenced by real-time confocal microscopy. J Neurosci 23:7337-7342. Medline

Lovatt D, Sonnewald U, Waagepetersen HS, Schousboe A, He W, Lin JH, Han X, Takano T, Wang S, Sim FJ, Goldman SA, Nedergaard M (2007) The transcriptome and metabolic gene signature of protoplasmic astrocytes in the adult murine cortex. J Neurosci 27:12255-12266. CrossRef Medline

MacAskill AF, Kittler JT (2010) Control of mitochondrial transport and localization in neurons. Trends Cell Biol 20:102-112. CrossRef Medline

MacAskill AF, Atkin TA, Kittler JT (2010) Mitochondrial trafficking and the provision of energy and calcium buffering at excitatory synapses. Eur J Neurosci 32:231-240. CrossRef Medline

Magi S, Arcangeli S, Castaldo P, Nasti AA, Berrino L, Piegari E, Bernardini R, Amoroso S, Lariccia V (2013) Glutamate-induced ATP synthesis: relationship between plasma membrane $\mathrm{Na}+/ \mathrm{Ca} 2+$ exchanger and excitatory amino acid transporters in brain and heart cell models. Mol Pharmacol 84:603-614. CrossRef Medline

Magistretti PJ (2006) Neuron-glia metabolic coupling and plasticity. J Exp Biol 209:2304-2311. CrossRef Medline

Magistretti PJ, Pellerin L (1999) Cellular mechanisms of brain energy metabolism and their relevance to functional brain imaging. Philos Trans $\mathrm{R}$ Soc Lond B Biol Sci 354:1155-1163. CrossRef Medline

McAllister AK (2004) Biolistic transfection of cultured organotypic brain slices. Methods Mol Biol 245:197-206. Medline

McKenna MC, Sonnewald U, Huang X, Stevenson J, Zielke HR (1996) Exogenous glutamate concentration regulates the metabolic fate of glutamate in astrocytes. J Neurochem 66:386-393. Medline

Meijering E, Dzyubachyk O, Smal I (2012) Methods for cell and particle tracking. Methods Enzymol 504:183-200. CrossRef Medline

Miller KE, Sheetz MP (2004) Axonal mitochondrial transport and potential are correlated. J Cell Sci 117:2791-2804. CrossRef Medline

Mironov SL (2007) ADP regulates movements of mitochondria in neurons. Biophys J 92:2944-2952. CrossRef Medline

Misko A, Jiang S, Wegorzewska I, Milbrandt J, Baloh RH (2010) Mitofusin 2 is necessary for transport of axonal mitochondria and interacts with the Miro/Milton complex. J Neurosci 30:4232-4240. CrossRef Medline

Morris RL, Hollenbeck PJ (1993) The regulation of bidirectional mitochondrial transport is coordinated with axonal outgrowth. J Cell Sci 104:917927. Medline

Morris RL, Hollenbeck PJ (1995) Axonal transport of mitochondria along microtubules and F-actin in living vertebrate neurons. J Cell Biol 131: 1315-1326. CrossRef Medline

Newman EA (2003) New roles for astrocytes: regulation of synaptic transmission. Trends Neurosci 26:536-542. CrossRef Medline

Ohno N, Kidd GJ, Mahad D, Kiryu-Seo S, Avishai A, Komuro H, Trapp BD (2011) Myelination and axonal electrical activity modulate the distribution and motility of mitochondria at CNS nodes of Ranvier. J Neurosci 31:7249-7258. CrossRef Medline 
Parpura V, Verkhratsky A (2012) Neuroglia at the crossroads of homoeostasis, metabolism and signalling: evolution of the concept. ASN Neuro 4:201-205. CrossRef Medline

Pellerin L, Magistretti PJ (1994) Glutamate uptake into astrocytes stimulates aerobic glycolysis: a mechanism coupling neuronal activity to glucose utilization. Proc Natl Acad Sci U S A 91:10625-10629. CrossRef Medline

Pellerin L, Magistretti PJ (1997) Glutamate uptake stimulates Na+, K+ATPase activity in astrocytes via activation of a distinct subunit highly sensitive to ouabain. J Neurochem 69:2132-2137. Medline

Peng L, Swanson RA, Hertz L (2001) Effects of L-glutamate, D-aspartate, and monensin on glycolytic and oxidative glucose metabolism in mouse astrocyte cultures: further evidence that glutamate uptake is metabolically driven by oxidative metabolism. Neurochem Int 38:437-443. CrossRef Medline

Quintero OA, DiVito MM, Adikes RC, Kortan MB, Case LB, Lier AJ, Panaretos NS, Slater SQ, Rengarajan M, Feliu M, Cheney RE (2009) Human Myo19 is a novel myosin that associates with mitochondria. Curr Biol 19:2008-2013. CrossRef Medline

Rizzuto R, Brini M, Pozzan T (1993) Intracellular targeting of the photoprotein aequorin: a new approach for measuring, in living cells, $\mathrm{Ca}(2+)$ concentrations in defined cellular compartments. Cytotechnology 11: S44-S46. CrossRef Medline

Rojas H, Colina C, Ramos M, Benaim G, Jaffe E, Caputo C, Di Polo R (2013) Sodium-calcium exchanger modulates the L-glutamate $\mathrm{Ca}(\mathrm{i})(2+)$ signalling in type-1 cerebellar astrocytes. Adv Exp Med Biol 961:267-274. CrossRef Medline

Rose CR, Ransom BR (1996) Mechanisms of $\mathrm{H}+$ and $\mathrm{Na}+$ changes induced by glutamate, kainate, and $\mathrm{D}$-aspartate in rat hippocampal astrocytes. J Neurosci 16:5393-5404. Medline

Rose EM, Koo JC, Antflick JE, Ahmed SM, Angers S, Hampson DR (2009) Glutamate transporter coupling to Na, K-ATPase. J Neurosci 29:81438155. CrossRef Medline

Schneider CA, Rasband WS, Eliceiri KW (2012) NIH Image to ImageJ: 25 years of image analysis. Nat Methods 9:671-675. CrossRef Medline

Schwarz TL (2013) Mitochondrial trafficking in neurons. Cold Spring Harb Perspect Biol 5:a011304. CrossRef Medline

Sheldon AL, Robinson MB (2007) The role of glutamate transporters in neurodegenerative diseases and potential opportunities for intervention. Neurochem Int 51:333-355. CrossRef Medline
Shimamoto K, Sakai R, Takaoka K, Yumoto N, Nakajima T, Amara SG, Shigeri Y (2004) Characterization of novel L-threo-beta-benzyloxyaspartate derivatives, potent blockers of the glutamate transporters. Mol Pharmacol 65:1008-1015. CrossRef Medline

Sontheimer H, Fernandez-Marques E, Ullrich N, Pappas CA, Waxman SG (1994) Astrocyte $\mathrm{Na}^{+}$channels are required for maintenance of $\mathrm{Na}^{+} /$ $\mathrm{K}^{+}$-ATPase activity. J Neurosci 14:2464-2475. Medline

Swanson RA (1992) Physiologic coupling of glial glycogen metabolism to neuronal activity in brain. Can J Physiol Pharmacol 70 [Suppl]:S138 S144. Medline

Taketo M, Yoshioka T (2000) Developmental change of GABA(A) receptormediated current in rat hippocampus. Neuroscience 96:507-514. CrossRef Medline

Waagepetersen HS, Qu H, Hertz L, Sonnewald U, Schousboe A (2002) Demonstration of pyruvate recycling in primary cultures of neocortical astrocytes but not in neurons. Neurochem Res 27:1431-1437. CrossRef Medline

Wang GJ, Jackson JG, Thayer SA (2003) Altered distribution of mitochondria impairs calcium homeostasis in rat hippocampal neurons in culture. J Neurochem 87:85-94. CrossRef Medline

Wang X, Schwarz TL (2009) The mechanism of Ca2+-dependent regulation of kinesin-mediated mitochondrial motility. Cell 136:163-174. CrossRef Medline

Whitelaw BS, Robinson MB (2013) Inhibitors of glutamate dehydrogenase block sodium-dependent glutamate uptake in rat brain membranes. Front Endocrinol (Lausanne) 4:123. CrossRef Medline

Yu AC, Schousboe A, Hertz L (1982) Metabolic fate of 14C-labeled glutamate in astrocytes in primary cultures. J Neurochem 39:954-960. CrossRef Medline

Yudkoff M, Nissim I, Pleasure D (1988) Astrocyte metabolism of [15N]glutamine: implications for the glutamine-glutamate cycle. J Neurochem 51:843-850. CrossRef Medline

Zerangue N, Kavanaugh MP (1996) Flux coupling in a neuronal glutamate transporter. Nature 383:634-637. CrossRef Medline

Zhang CL, Ho PL, Kintner DB, Sun D, Chiu SY (2010) Activity-dependent regulation of mitochondrial motility by calcium and $\mathrm{Na} / \mathrm{K}-\mathrm{ATPase}$ at nodes of Ranvier of myelinated nerves. J Neurosci 30:3555-3566. CrossRef Medline 